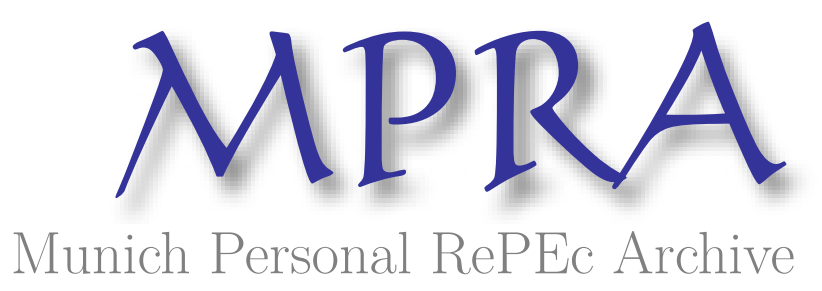

\title{
Keynesian Beauty Contest, Accounting Disclosure, and Market Efficiency
}

Gao, Pingyang

The University of Chicago - Graduate School of Business

June 2007

Online at https://mpra.ub.uni-muenchen.de/9480/

MPRA Paper No. 9480, posted 08 Jul 2008 00:51 UTC 


\title{
Keynesian Beauty Contest, Accounting Disclosure, and Market Efficiency*
}

Pingyang $\mathrm{Gao}^{\dagger}$

Yale School of Management

October, 2007

\begin{abstract}
This paper examines the market efficiency consequences of accounting disclosure in the context of stock markets as a Keynesian beauty contest, an influential metaphor originally proposed by Keynes (1936) and recently formalized by Allen, Morris, and Shin (2006). In such markets, public information plays an additional commonality role, biasing stock prices away from the consensus fundamental value toward public information. Despite this bias, I demonstrate that provisions of public information always drive stock prices closer to the fundamental value. Hence, as a main source of public information, accounting disclosure enhances market efficiency, and transparency should not be compromised on grounds of the Keynesian-beauty-contest effect.
\end{abstract}

*I am grateful to seminar participants at Yale University, the 2007 AAA northeast region meeting, and the 2007 AAA Chicago meeting. I sincerely thank Rick Antle, Paul Fischer (discussant), John Geanakoplos, Jonathan Glover, Dong Lou, Brian Mittendorf, Robert Shiller, Shyam Sunder, Jacob Thomas, Robert E. Verrecchia, Varda Yaari (discussant), Hongjun Yan, Frank Zhang, and Yun Zhang for helpful comments. All errors are my own.

${ }^{\dagger}$ Email: pingyang.gao@yale.edu 


\section{Introduction}

I investigate how the quality of accounting disclosure influences market efficiency in the context of stock markets as a Keynesian beauty contest, a metaphor first introduced by Keynes (1936). At that time, a London newspaper was running a beauty contest in which readers were asked to select a set of six "most beautiful" pictures from 100 photographs of women. Whoever picked the most popular pictures was entitled for a raffle prize. To win the competition, players should not naively select six faces they believed the most beautiful; instead, they should use their information to infer which faces other players would believe the prettiest and other players would believe that other players would believe the prettiest and so on. Keynes observed that stock markets shared the essence of this competition, in that the actions of many rational but short-horizon investors were similarly governed by their expectations about what other investors believed, rather than by their genuine expectations about the true value of a firm.

Allen, Morris, and Shin (2006) rationalize this Keynesian-beauty-contest effect as a consequence of investors' short horizons. Since a short-horizon investor exits a firm before its fundamental value is known, her payoff depends on how much other investors would like to pay, rather than on how much she expects the fundamental value of the firm will be. Given access to both public and private information, she puts an extra weight on public information due to its dual role. Public information plays an information role because it conveys information about the unknown fundamental value (hereafter the information role); meanwhile, public information plays a commonality role because it is common to the information sets and demand functions of all investors (hereafter the commonality role). Although the noise terms in both the public and private signals enter the individual demands of investors, the independent noise terms in the private signals cancel out when 
the individual demands are aggregated. But the noise in the public signal remains in the aggregate demand because the individual demands share the same noise term. As a result, the public signal influences the price above and beyond its information value. This additional commonality role of pubic information biases stock prices away from the consensus fundamental value toward public information.

Having qualitatively formalized the Keynesian-beauty-contest effect, Allen, Morris, and Shin (2006) also leave many questions open, one of which concerns the market efficiency consequences of disseminating public information in a Keynesian-beauty-contest stock market. How does the quality of public information affect market efficiency? How is the intensity of the dual role of public information related to its quality? Could the Keynesian-beauty-contest effect justify the withdrawal of some noisy public information?

These questions are important to accounting researchers. The Keynesian-beauty-contest effect provides a new perspective on understanding accounting disclosure. Accounting disclosure, as a main source of public information, is a unique feature of public firms characterized by dispersed ownership. Understanding accounting disclosure entails examining the consequences of dispersed ownership, among which agency problems and differential information have been the best known. However, dispersed ownership has other consequences that have profound impact on disclosure practice but have not received the attention they deserve. One of such examples is the Keynesianbeauty-contest effect. The effect results from investors' short horizons, which in turn arise because dispersed ownership of modern corporations decouples the life span of entrepreneurs and owners from that of their firms.

In the absence of a formal rational interpretation of the Keynesian-beauty-contest effect, the extra weight on public information may induce people to speculate that transparency should be 
curtailed in a Keynesian-beauty-contest stock market. As public information becomes noisy, its information value becomes tenuous. If its commonality role increases or at least does not decrease as public information becomes less precise, there could exist a threshold precision under which the diminishing information role is dominated by the non-decreasing commonality role. This kind of conventional wisdom could have immediate prescriptive implications.

This paper formally evaluates the market efficiency consequences of disseminating public information in a rational Keynesian-beauty-contest stock market. Built on Allen, Morris, and Shin (2006), the paper solves for a closed-form equilibrium of a two-trading-period noisy rational expectations model. The comparative statics then show that more public information always drives stock prices closer to the fundamental value, even in the presence of the Keynesian-beauty-contest effect. Therefore, in a rational competitive market, provisions of more and better accounting disclosure boost the overall informativeness of stock prices to market participants, and transparency should not be compromised on grounds of the Keynesian-beauty-contest effect. Prohibition of public information, however noisy it is, amounts to "throwing the baby out with the bathwater".

The rationale for the positive market efficiency effect of public information lies in the endogenous link between the dual role of public information. The information role and the commonality role are connected through the quality of public information. Contrary to the conventional wisdom, the commonality role decreases as public information becomes less accurate. That is, when public information becomes noisier, not only do short-horizon investors use it less, they also overuse it less. The intuition is straightforward. The commonality role occurs because short-horizon investors correctly believe in the first place that other investors will be using public information due to its information value. When the information value of public information becomes thinner, investors overuse it less because they again correctly believe that others will be using it less. In the extreme, 
if a piece of public information is completely useless, it will be neither used nor overused. Just as Morris and Shin (2002) differentiate the Keynesian-beauty-contest effect from the sunspot literature based on the fact that public information has the information role, the endogenous link between the dual role of public information is a hallmark of the rational Keynesian-beauty-contest effect.

The endogenous link between the dual role of public information reconciles this study with Morris and Shin (2002). Assuming that agents have a fixed "beauty contest" component of utility for keeping their actions closer to the average action of others, Morris and Shin (2002) conclude that noisy public information could be detrimental to social welfare. Despite the modeling differences, the discussion in the last two paragraphs suggests that their conclusion may be due to the assumed beauty contest utility, which, by fixing the intensity of the commonality role, divorces the link between the dual role of public information. Hence, the comparison of the two studies deepens our knowledge of the Keynesian-beauty-contest effect.

This paper also contributes to the literature on dynamic noisy rational expectations in capital market by supplying a closed-form equilibrium, which is rare in this literature. ${ }^{1}$ This paper is an extension to the work in Brown and Jennings (1989) and Allen, Morris, and Shin (2006) who conduct only qualitative analysis. Besides making it possible to analyze the market efficiency consequences of public information, the closed-form equilibrium opens up many other possibilities. For example, the model could be developed to study firms' choice between private and public channels to convey information to stock markets. Private information is only partially reflected in stock price while

\footnotetext{
${ }^{1}$ Grossman (1976), Grossman and Stiglitz (1980), Diamond and Verrecchia (1981), and Admati (1985) study a single-period noisy rational expectations model; Besides Allen, Morris, and Shin (2006), see also Brown and Jennings (1989) and Grundy and McNichols (1989) for multi-period noisy rational expectations models. Anctil, Dickhaut, Kanodia, and Shapiro (2004),Walther (2004) (discussion), and Hirota and Sunder (2007) conduct interesting laboratory experiments on the Keynesian-beauty-contest effect.
} 
public information is overused in stock markets. Firms may benefit from a balanced combination of both channels. For another example, the relation between information quality and cost of capital has been extensively studied in a single-period model (see Easley and O'hara, 2004; Lambert, Leuz, and Verrecchia, 2007b,a, e.g.). A tractable dynamic model could help reexamine the relation in the context of stock markets as a Keynesian beauty contest. In addition, the model may also find applications in the vast ERC literature.

The rest of the paper is organized as follows. Part 2 describes the basic setting of the model; part 3 defines and solves for the equilibrium; part 4 examines the market efficiency consequences of accounting disclosure; and part 5 concludes.

\section{The Model}

I describe the basic setting of the model in this section, which closely follows Brown and Jennings (1989) and Allen, Morris, and Shin (2006). It is a two-trading-period noisy rational expectations economy with short-horizon investors and independent supply shocks.

There are two trading periods. A risk free asset and a firm's risky stocks are traded in both periods in a competitive market. The risk free asset acts as the numeraire of the economy and its return is normalized to be zero. The per share random payoff of the firm's stocks, denoted as $\theta$, is unknown to investors until the end of the last period.

Investors' short horizons are characterized by the overlapping generations assumption. There are two generations of investors and each generation have a continuum of investors indexed by an interval $[0,1]$. Each generation only live in one period and transfer their ownership of the firm to the next generation through trading. Young investors are born with endowment and save through the 
market; at the end of their life period, they become old, sell their stocks and consume the proceeds. For the purpose of this study, I end the overlapping generations cycle at the end of period 2 by the liquidation of the firm. Figure 1 describes the time line of events.

\begin{tabular}{lll}
\hline & & \\
$\begin{array}{l}\text { Public information is disclosed } \\
\text { Young investors are }\end{array}$ & $t=2$ & The firm is \\
born with private & young investors are & liquidated and \\
information and wealth; & born with private & $\theta$ is revealed. \\
They buy stocks in order to & information and wealth; \\
resell them at $t=2$. & They buy stocks in order to \\
& liquidate the firm at \\
& $t=3$.
\end{tabular}

Figure 1 The Time Line of Events

Investors have access to both private and public information, with the later disclosed by the firm. Conditional on $\theta$, each investor $i$ in period $t$ receives an independent private signal $\tilde{x}_{t i}$, $t \in\{1,2\}$ and $i \in[0,1]$, with precision $\beta$. The realization of the private signal is $x_{t i}$.

$$
\tilde{x}_{t i}=\theta+\tilde{\epsilon}_{t i}, \tilde{\epsilon}_{t i} \sim N\left(0, \frac{1}{\beta}\right)
$$

Note that the aggregate private information fully reveals the fundamental value, due to the assumption of a competitive market. This design is only for convenience. The general results hold if the pooling of private information is not perfect. We can either use a finite number of investors or assume a common error in investors' private signals to prevent the pooling of private information from fully revealing the fundamental value.

At the beginning of period 1 , the firm discloses an independent public signal, $\tilde{z}$, with precision 
$\alpha$. The realization of the public signal is $z$.

$$
\tilde{z}=\theta+\tilde{\epsilon}_{z}, \tilde{\epsilon}_{z} \sim N\left(0, \frac{1}{\alpha}\right)
$$

Although the only public information in the model is the firm's disclosure, the main results still hold if other public information sources are modeled. The linear property of multivariate normal distribution allows other public information to be summarized in $\alpha$. More other public information indicates a higher lower bound of $\alpha$. Similarly, allowing the firm to disclose another independent signal at the beginning of period 2 does not affect the main results, either.

While the firm could make its information public according to a pre-announced disclosure policy, investors can not communicate with each other except through stock price. ${ }^{2}$ Investors learn about other investors' private information through stock price. The learning is not perfect because stock prices are contaminated by information irrelevant trading. Following the tradition from Grossman and Stiglitz (1980) and Diamond and Verrecchia (1981), I use supply noise to summarize all forces other than information that affect stock prices. The random per capita supply noise of the firm's shares in period $t, \tilde{s}_{t}, t \in\{1,2\}$, is normally distributed with mean zero and precision $\gamma_{t}$, respectively. The supply shocks are independent of all signals and of each other. ${ }^{3}$

A typical investor, $i$, has a CARA utility function

$$
U_{i}(c)=-e^{-\frac{c_{i}}{\tau}}
$$

\footnotetext{
${ }^{2}$ This paper does not explicitly study choices of the firm's disclosure policy. However, given the definition of information, the firm's disclosure policy can be characterized by choosing a parameter $\alpha$ from the interval $\left[0, \alpha_{\max }\right]$. A choice of $\alpha=0$ means that the firm does not disclose anything, a choice of $\alpha=\alpha_{m a x}$ indicates a policy of disclosing everything the firm knows, and a choice of an interior $\alpha$ is equivalent to a partial disclosure policy by which the firm adds some white noise to its information and discloses the garbled signal.

${ }^{3}$ See Grossman (1995) and Black (1986) for discussions about the nature and source of supply noise.
} 
where $c_{i}$ is her consumption financed by selling or liquidating her holdings when she becomes old, and $\tau$ is her risk tolerance which is the same across investors. By solving the expected utility maximization problem, we get her demand for stocks, which is linear in information.

$$
D_{i}=\frac{\tau\left(E_{i}\left[\tilde{\mu} \mid I_{i}\right]-p\right)}{\operatorname{Var}_{i}\left[\tilde{\mu} \mid I_{i}\right]}
$$

where $\tilde{\mu}$ is the random payoff from holding stocks, $E_{i}\left[\tilde{\mu} \mid I_{i}\right]$ and $\operatorname{Var}_{i}\left[\tilde{\mu} \mid I_{i}\right]$ represent investor $i$ 's estimates of the mean and variance of the random payoff conditional on her information set $I_{i}$, and $\mathrm{p}$ is the stock price. I denote the stock prices in period 1 and 2 using $p_{1}$ and $p_{2}$, respectively. Note that investors in period 1 expect a payoff of $p_{2}$ while investors in period 2 is rewarded by the firm's fundamental value $\theta$. Short horizons induce investors in period 1 to be concerned with the interim price $p_{2}$, rather than the fundamental value $\theta$. For convenience, I also assume that information quality, precisions of supply noise, and investors' risk tolerance are well defined. That is, $\alpha, \beta, \gamma_{1}$, $\gamma_{2}$ and $\tau$ are positive and finite.

\section{The Equilibrium}

In this section, I characterize the unique linear rational expectations equilibrium of the model in Proposition 1, and compare the closed-form equilibrium with the previous literature.

\subsection{The Equilibrium}

A rational expectations equilibrium of the short-horizon economy is defined as a pair of prices $\left(p_{1}\right.$, $\left.p_{2}\right)$ that satisfies

a. The stock market clears in both period 1 and 2 ; 
b. Investors maximize their expected utilities, conditional on all available information, including the information gleaned from stock price;

c. Investors have rational expectations. Their beliefs about all random variables are consistent with the true underlying distributions;

d. Prices depend on information only through supply and demand.

In addition, if $\left(p_{1}, p_{2}\right)$ are linear functions of information and supply noise, then the equilibrium is a linear rational expectations equilibrium.

Proposition 1. There is a unique linear rational expectations equilibrium $\left(p_{1}, p_{2}\right)$, characterized by

$$
\begin{aligned}
& p_{1}=b z+c \theta-d s_{1} \\
& p_{2}=\frac{1}{\alpha+\beta+\rho+\rho_{2}}\left[\alpha z+\left(\beta+\rho+\rho_{2}\right) \theta-\frac{\beta+\rho_{2}}{\rho_{2}} \frac{\rho}{\beta \tau} s_{1}-\frac{\left(\beta+\rho_{2}\right)}{\beta \tau} s_{2}\right]
\end{aligned}
$$

where 


$$
\begin{aligned}
b & =\frac{\alpha}{\alpha+\rho+\beta M} \\
c & =\frac{\rho+\beta M}{\alpha+\rho+\beta M} \\
d & =\frac{\beta+\rho_{2}}{\rho_{2}} \frac{\rho+\beta M}{\alpha+\rho+\beta M} \frac{1}{\beta \tau} \\
M & =\frac{\beta+\rho_{2}}{\alpha+2 \beta+\rho+\rho_{2}} \\
\rho & =k \rho_{1} \\
\rho_{1} & =\beta^{2} \tau^{2} \gamma_{1} \\
\rho_{2} & =\beta^{2} \tau^{2} \gamma_{2} \\
k & =\left(\frac{\rho_{2}}{\beta+\rho_{2}}\right)^{2}
\end{aligned}
$$

All proofs are placed in the Appendix. The proof of Proposition 1 involves backward induction by solving for $p_{2}$ first. The basic idea is to assume a linear price function, plug in the assumed price function to investors' demand functions, obtain a new price function by equating aggregate demand with aggregate supply, and then compare coefficients of the two price functions to determine the coefficients in the assumed price function.

We will focus on $p_{1}$ to accentuate the influence of short horizons. In contrast, investors in period 2 receive the liquidation value of the firm. Thus, $p_{2}$ is only used to terminate the overlapping generations cycle and establish an anchor from which we can apply backward induction to solve for $p_{1}$. Unless explicitly noted, from now on, by price I mean $p_{1}$.

The commonality role of public information, the extra weight on public information in the price function, and the Keynesian-beauty-contest effect of the market are three equivalent concepts. When investors have short horizons, stock prices depend on investors' expectations of the average expectation of the fundamental value. Public information, as common knowledge among investors, 
plays an additional commonality role of anchoring investors' beliefs about other investors' beliefs, causing investors to overuse it. As a result, stock prices have an extra weight on public information relative to private information, and the Keynesian-beauty-contest effect occurs.

To characterize the Keynesian-beauty-contest effect, I use as the benchmark the weight on public information in a long-horizon economy in which the firm's value is revealed at the end of period $1 .^{4}$ It is a long-horizon economy because investors' horizons are as long as the firm's life span. This long-horizon benchmark, characterized in Lemma 1, emphasizes on the fact that the Keynesian-beauty-contest effect is attributable to investors' short horizons. I denote all the variables in this long-horizon case using the same notations with a top "^". For example, the price in this long-horizon economy is " $\hat{p}_{1}$ ".

Lemma 1. The long-horizon equilibrium is described by $\hat{p}_{1}$.

$$
\hat{p}_{1}=\hat{b} z+\hat{c} \theta-\hat{d} s_{1}
$$

where

$$
\begin{aligned}
\hat{b} & =\frac{\alpha}{\alpha+\beta+\rho_{1}} \\
\hat{c} & =\frac{\beta+\rho_{1}}{\alpha+\beta+\rho_{1}} \\
\hat{d} & =\frac{1}{\beta \tau} \frac{\beta+\rho_{1}}{\alpha+\beta+\rho_{1}} \\
\rho_{1} & =\beta^{2} \tau^{2} \gamma_{1}
\end{aligned}
$$

\footnotetext{
${ }^{4}$ Allen, Morris, and Shin (2006) use as the benchmark the consensus fundamental value in the short-horizon economy. The two benchmarks are only slightly different. Moreover, the difference does not affect the main results but makes the interpretation easier, as we shall see soon. In addition, Allen, Morris, and Shin (2006) define a longhorizon economy as one in which investors live longer than one period, resulting in difficulty in solving for a close-form equilibrium.
} 
Note that $\hat{p}_{1}$ differs from $p_{2}$, although both are generated in a long-horizon economy. $p_{2}$ is not directly comparable to $p_{1}$ because investors in period 2 have additional access to price $p_{1}$ which conveys the private information of investors in period 1.

Figure 2 summarizes the relation between the short-horizon and long-horizon equilibria by comparing the first-best price $p_{f b}$, the expected long-horizon price $E_{s 1} \hat{p}_{1}$, and the expected shorthorizon price $E_{s 1} p_{1}$. Given the focus on the impact of public information, we use the expected prices with respect to supply noise to get around the confounding effect of supply noise.

\begin{tabular}{|c|c|c|c|}
\hline\llcorner & $\perp$ & $\perp$ & $\dashv$ \\
\hline$z$ & $E_{s_{1}} p_{1} \neq \bar{E}_{1}\left[\theta \mid I_{1}\right]$ & $E_{s_{1}} \hat{p}_{1}=\bar{E}_{1}\left[\theta \mid \hat{I}_{1}\right]$ & $p_{f b}=\theta$ \\
\hline $\begin{array}{l}\text { Public } \\
\text { information }\end{array}$ & Short-horizon price & Long-horizon price & $\begin{array}{l}\text { The first } \\
\text { best price }\end{array}$ \\
\hline
\end{tabular}

Figure 2: The Keynesian Beauty Contest and the Noise Effect

$\bar{E}_{1}[\cdot]$ is the operator of the consensus by taking the average of investors' expectations in period 1. Since investors learn from different prices in two economies, $p_{1}$ and $\hat{p}_{1}, \hat{I}_{1}$ is slightly different from $I_{1}$, resulting in the difference between two metrics of the consensus fundamental value, $\bar{E}_{1}\left[\theta \mid I_{1}\right]=\frac{\alpha}{\alpha+\beta+\rho} z+\frac{\beta+\rho}{\alpha+\beta+\rho} \theta$ and $\bar{E}_{1}\left[\theta \mid \hat{I}_{1}\right]=\frac{\alpha}{\alpha+\beta+\rho_{1}} z+\frac{\beta+\rho_{1}}{\alpha+\beta+\rho_{1}} \theta$. However, because both $\rho$ and $\rho_{1}$ are independent of $\alpha$, using either of them as a benchmark for the extra weight does not qualitatively affect the main results. Thus, for ease of exposition, I omit their difference in the subsequent discussion.

$p_{f b}$ is the fundamental value or the first-best price when there are neither supply noise nor short horizons. Supply noise prevents the full expression of private information in stock price. 
This noise effect drives the expected long-horizon price, $E_{s_{1}} \hat{p}_{1}$, away from the fundamental value toward public information. One prominent feature of the noise effect is that $E_{s_{1}} \hat{p}_{1}$ coincides with the consensus fundamental value, $\bar{E}_{1}\left[\theta \mid \hat{I}_{1}\right] .{ }^{5}$ The Keynesian-beauty-contest effect is characterized by the further deviation of $E_{s_{1}} p_{1}$ from $E_{s_{1}} \hat{p}_{1}$ toward public information. The Keynesian-beautycontest effect differs from the noise effect in that $E_{s_{1}} p_{1}$ deviates from the consensus fundamental value, either $\bar{E}_{1}\left[\theta \mid I_{1}\right]$ or $\bar{E}_{1}\left[\theta \mid \hat{I}_{1}\right]$. Thus, although both the Keynesian-beauty-contest effect and the noise effect bias stock prices toward public information, the discrepancy between $E_{s_{1}} p_{1}$ and the consensus fundamental value in the Keynesian-beauty-contest effect provides a useful clue to empirically differentiate the two effects.

\subsection{The Comparison with the Previous Literature}

Having presented the closed-form equilibrium in Proposition 1, I briefly compare the solution of the model with the results in the previous literature on multi-period noisy rational expectations economies with short-horizon investors, mainly Brown and Jennings (1989) and Allen, Morris, and Shin (2006). ${ }^{6}$

This paper is an extension to Allen, Morris, and Shin (2006). They propose that the Keynesianbeauty-contest effect could arise rationally from investors' short horizons, and prove the key results

\footnotetext{
${ }^{5}$ The inability of private information to be fully reflected in stock price resembles the mechanism underlying the rational herding effect in which a subsequent actor can not fully learn her predecessors' private information because she can only observe their actions but not their private information. In this sense, the noise effect in a noisy rational expectations model is analogous to the rational herding effect, although the later usually concerns only about discrete actions (see Bikhchandani, Hirshleifer, and Welch, 1998, e.g.).

${ }^{6}$ In contrast, Grundy and McNichols (1989) study a two-period noisy rational expectations economy in which investors trade in both periods and thus have horizons as long as the firm's life. They also use a different information structure.
} 
without deriving a closed-form solution. ${ }^{7}$ Built on their paper, I characterize a closed-form equilibrium of their model and identify its implications for the desirability of public information in a Keynesian-beauty-contest stock market.

Papers on a multi-period noisy rational expectations model usually do not derive a closed-form equilibrium. For example, two main papers in this literature, Brown and Jennings (1989) and Allen, Morris, and Shin (2006), demonstrate their themes based on qualitative characterization. To show their main point that technical analysis has value in a short-horizon economy, Brown and Jennings (1989) prove the existence of the correlation between the historical price and the fundamental value conditional on the current price. To rationalize the Keynesian-beauty-contest effect and demonstrate the role of high-order beliefs in asset pricing, Allen, Morris, and Shin (2006) prove the existence of an extra weight on public information in the price function.

There are at least two challenges in characterizing a closed-form equilibrium for a multi-period noisy rational expectations economy. First, investors who can trade multiple times establish extra positions to hedge their demands in later periods. The form of the extra hedging demands is often complicated. Brown and Jennings (1989) are the first to circumvent this issue by introducing shorthorizon investors who only live in one period and have to close their positions at the end of their life. Second, learning from stock price under a general correlation structure of noisy supplies across periods is highly non-linear. Allen, Morris, and Shin (2006) assume independent noisy supplies to enhance tractability of their T-period model. I further exploit both features of short horizons and

\footnotetext{
${ }^{7}$ Allen, Morris, and Shin (2006) have also studied a two-period model in the appendix to their paper, as an illustration of the general T-period model in the main text. Their price function $p_{1}$ is given on page 747 of their paper. With the presence of $\operatorname{Var}_{1}\left(p_{2}\right), \operatorname{Var}_{1}(\theta)$ and other non-linear components, the system of the three equations from coefficient comparison at the top of page 747 becomes highly nonlinear, and $p_{1}$ is expressed as a function of intermediary variables.
} 
independent noisy supplies to solve for the closed-form equilibrium. In particular, the key steps are to focus on deriving the closed-form expressions of the precisions ( $\rho$ and $\rho_{2}$ ) investors learn from stock prices. With the explicit solution of $\rho_{2}$, we can solve for the explicit expression of $p_{2}$, which is the forecasting target of investors in period 1. Then, we can get the closed-form solutions of $\rho$ and $p_{1}$.

To see the evolution from Brown and Jennings (1989) and Allen, Morris, and Shin (2006) to this paper, we can use the closed-form equilibrium to corroborate their qualitative results. One of the equivalent conditions under which technical analysis has value is that $p_{1}$ is not redundant in determining $D_{2 i}$, the demand function of some investor $i$ in period $2 .{ }^{8}$ From the proof of Proposition 1 in the appendix, $D_{2 i}$ is given as follows.

$$
D_{2 i}=\tau\left[\left(\alpha-\frac{b}{c} \rho-\frac{b_{2}}{c_{2}} \rho_{2}\right) z+\left(\frac{1}{c} \rho-\frac{a_{2}}{c_{2}} \rho_{2}\right) p_{1}+\beta x_{2 i}-\left(\alpha+\rho+\beta+\left(1-\frac{1}{c_{2}}\right) \rho_{2}\right) p_{2}\right]
$$

Conditional on $z, x_{2 i}$, and $p_{2}$, the incremental weight on the historical price $p_{1}$ is not zero because

$$
\tau\left(\frac{1}{c} \rho-\frac{a_{2}}{c_{2}} \rho_{2}\right)=\frac{\beta \rho(\alpha+\beta+\rho)\left(\alpha+\beta+\rho+\rho_{2}\right) \tau}{\left(\beta+\rho_{2}\right)\left(\beta^{2}+\rho\left(\alpha+\rho+\rho_{2}\right)+\beta\left(2 \rho+\rho_{2}\right)\right)} \neq 0
$$

Therefore, technical analysis, or the analysis of historical prices, does have value. Furthermore, since we have obtained the closed-form expressions of $\rho$ and $\rho_{2}$, we could also analyze how the quality of public information affects the additional value of historical prices in technical analysis. I leave this topic to future research.

We could also use the closed-form equilibrium to confirm the main theme in Allen, Morris, and Shin (2006) that the rational Keynesian-beauty-contest effect could arise from investors' short horizons. The existence of the Keynesian-beauty-contest effect is equivalent to $b>\hat{b}$. That is, there

\footnotetext{
${ }^{8}$ See page 534 of Brown and Jennings (1989).
} 
is an extra weight on public information above and beyond its information value. Apparently,

$$
b-\hat{b}=\frac{\alpha}{\alpha+\rho_{1} k+\beta M}-\frac{\alpha}{\alpha+\rho_{1}+\beta}>0
$$

since $k<1$ and $M<1$.

Moreover, because we have derived the explicit expressions of $b$ and $\hat{b}$, we can examine the properties of the Keynesian-beauty-contest effect beyond its existence. This paper focuses on one of these other properties: how changes in the quality of public information affect the informativeness of stock prices as signals of the fundamental value. In a Keynesian-beauty-contest stock market, the information role of public information makes the stock price a more accurate signal of the fundamental value, whereas the commonality role of public information drives the stock price away from the fundamental value. The overall impact of public information on market efficiency is thus a trade-off between these two opposing forces and the answer is not straightforward. For example, one extreme case is to eliminate the Keynesian-beauty-contest effect by prohibiting public information. As $\alpha$ goes to zero, the weight on public information approaches zero in both the longand short-horizon economies and the Keynesian-beauty-contest effect vanishes. In this case, does the withdrawal of public information drive stock prices closer to the fundamental value? While investors put no weight on the noise in the public signal, they are now putting more weight on the supply noise. ${ }^{9}$ The net effect of withdrawing some noisy public information is therefore ambiguous. I formally study this issue in the rest of the paper.

\footnotetext{
${ }^{9}$ This is the case because $\mathrm{d}$ is decreasing in $\alpha$.
} 


\section{Keynesian Beauty Contest and Market Efficiency}

While there are many metrics measuring market efficiency, I focus on price efficiency, the accuracy with which stock prices reflect the fundamental value (see Tobin, 1984, e.g). The primary goal of financial reporting is to provide various market participants with information about a business enterprise's fundamental value (see FASB, 1978, e.g.). Meanwhile, one basic function of markets, stock markets included, is to aggregate and disseminate value relevant information inherently dispersed among market participants (see Hayek, 1945, e.g.). To the extent that I examine the impact of the quality of accounting disclosure on the price discovery function of stock markets, price efficiency is a proper measure.

By adhering to my definition of market efficiency, I try to avoid unnecessary confusion of terminology. In the theoretical literature on noisy rational expectations in capital markets, price efficiency is sometimes labeled as informational efficiency, as opposed to allocational efficiency based on Pareto-efficiency in a general equilibrium (see Brunnermeier, 2001, e.g.). The label "informational" is inevitably confused with the empirical definition of market efficiency by Fama (1970). Moreover, despite the possible divergence, two types of efficiency are closely related. ${ }^{10}$ In a much richer model, more accurate prices could enable market participants to make better informed decisions with respect to resource allocation. To that extent, price efficiency may also be viewed as a reduced-form counterpart of the Pareto-efficiency-based definition of market efficiency, such as the one in Grossman (1995).

Price efficiency is measured using the reciprocal of the mean-squared error (MSE) between a firm's fundamental value and its stock prices, a traditional measure of the extent to which markets

\footnotetext{
${ }^{10}$ Hirshleifer (1971) provides an example of the possible divergence.
} 
fulfill the price discovery function. In statistical terms, price efficiency emphasizes on the efficiency property of stock prices as an estimator of the fundamental value. Lower MSE implies that stock prices are much closer to the fundamental value, resulting in higher market efficiency.

$$
P E=\frac{1}{E_{s, z}[p-\theta]^{2}}
$$

$\mathrm{PE}$ is an ex ante measure. $E_{s, z}[\cdot]$ means that the expectation is taken with respect to both supply noise and public information.

Given the presence of the Keynesian-beauty-contest effect, how could we improve market efficiency through accounting disclosure? Proposition 2 answers this question.

Proposition 2. More public information uniformly improves market efficiency, even in the presence of the Keynesian-beauty-contest effect.

In the context of stock markets as a Keynesian beauty contest, transparency is still a worthwhile cause. Accounting disclosure provides information about the future cash flow of a firm. Although short-horizon investors overuse it, provisions of more and better financial reporting still boost the overall informativeness of stock prices to market participants. The fact that stock markets behave like a Keynesian beauty contest does not justify the withdrawal of public information.

Public information affects market efficiency through its dual role: the information role and the commonality role. The former improves price efficiency while the later potentially reduces price efficiency. In the absence of a formal examination of the relation between the two roles, we may conjecture that prohibition of some noisy public information may be necessary to enhance market efficiency in a Keynesian-beauty-contest stock market. As public information becomes less precise, its information value is attenuated. If the commonality role increases or at least does 
not decrease in the variance of public information, there could exist a threshold of the precision of public information under which the diminishing information role is dominated by the non-decreasing commonality role.

Proposition 2 contradicts such a conjecture. It implies that while public information plays the dual role, the information role always dominates the commonality role. Since the information role dissipates as public information becomes less precise, a necessary condition for the dominance is that the commonality role decreases in the variance of public information. That is, the dual role of public information is endogenously linked through the quality of public information. I verify this intuition by showing that the Keynesian-beauty-contest effect intensifies as public information becomes more accurate.

Before proceeding to the endogenous link between the dual role of public information, there is one caveat about Proposition 2. The conclusion is obtained in a competitive equilibrium in which the action (demand) of any atomistic investor does not affect the price and thus the actions (demands) of other investors. While this result establishes an important benchmark for the desirability of public information in a competitive market, there could be other channels through which public information reduces the overall informativeness of market prices. In this broad sense, Shiller (2000) suggests that news media exert undue influence on market events by promulgating information and thus creating "similar thinking among large groups of people." One prominent approach, which has been advanced lately and may substantiate Shiller's arguments, is to model explicit coordination motivations among agents. For example, Plantin, Sapra, and Shin (2007) create explicit coordination issues among financial institutions by introducing the (il)liquidity of the market for selling financial assets. ${ }^{11}$ Their selling decisions become strategic substitutes under the

\footnotetext{
${ }^{11}$ The August 2007 issue of The Economist has a concise summary of the main effects in Plantin, Sapra, and Shin
} 
regime of historical cost accounting, and strategic complements under the regime of mark-to-market accounting. By coordinating financial institutions' selling decisions, mark-to-market accounting injects "endogenous" and "artificial" volatility to the market price, degrading its information value. Thus, the attempt to use the information contained in prices destroys the information value of prices. Although they do not model the impact of public information on market efficiency, their approach may be used to construct examples with different conclusions on the desirability of public information. In sum, Proposition 2 sets an important benchmark for the welfare effect of public information in a competitive market; it will be interesting to explore what kind of market frictions could change the conclusions in this benchmark case.

Bearing this caveat in mind, we resume the investigation of the relation between the dual role of public information to gain better intuition behind Proposition 2. As discussed before, the Keynesian-beauty-contest effect of stock market, the commonality role of public information, and the extra weight on public information in stock price are three equivalent concepts. Using as the benchmark the weight on public information in the long-horizon economy, we could quantify the Keynesian-beauty-contest effect as the discrepancy between the weights on public information in $p_{1}$ and $\hat{p}_{1}$.

I define the extra weight on public information, $\mathrm{R}$, as follows.

$$
R=1-\frac{1}{\frac{b}{c} / \frac{\hat{b}}{\hat{c}}}
$$

Since the ratio $\frac{b}{c}\left(\frac{\hat{b}}{\hat{c}}\right)$ reflects the relative use of public and private information when investors have short (long) horizons, the ratio $\frac{b}{c} / \frac{\hat{b}}{\hat{c}}$ represents the extent to which public information is overused by short-horizon investors. The monotonic transformation in definition 8 normalizes $\mathrm{R}$ to (2007). 
lie between zero and one. The greater $\mathrm{R}$ is, the more salient the Keynesian-beauty-contest effect.

Proposition 3. The Keynesian-beauty-contest effect intensifies as public information becomes more precise.

Since we have solved for the closed-form equilibrium, we can show here the determinant of the intensity of the Keynesian-beauty-contest effect. The commonality role is connected to the information role through the quality of public information. When the quality of public information improves, the Keynesian-beauty-contest effect becomes more salient and the price concentrates further on public information. The intuition for this link is straightforward. The Keynesianbeauty-contest effect occurs because public information has information value in the first place. Anticipating that other investors will be using public information to forecast the fundamental value, a short-horizon investor, who tries to forecast the consensus fundamental value, overuses public information over and above its optimal use in assessing the fundamental value. As it becomes more accurate, not only does she use public information more due to its improved information value, she also overuses it further because of its enhanced commonality role of forecasting the consensus fundamental value. Just as Morris and Shin (2002) differentiate the Keynesian-beauty-contest effect from the sunspot literature based on the fact that public information has the information role, the endogenous link between the dual role of public information is a hallmark of the rational Keynesian-beauty-contest effect.

This endogenous link between the information role and the commonality role of public information is crucial in the market efficiency consequences of public information. Short horizons create interdependency of investors' demands for stocks and give rise to the dual role of public information. The dual role is endogenously connected to each other in such a way that the commonality 
role is always secondary to the information role in terms of market efficiency.

In contrast, if the dual role of public information is directly assumed, as opposed to being derived from short horizons, the endogenous link is then muted. Consequently, when the information value is tenuous while the commonality role is strong enough, noisy public information could decrease market efficiency. Morris and Shin (2002) prove a similar point. In their game theory model, besides a standard component of utility defined over the distance between her action and the true state, an agent's loss function has an additional "beauty contest" component with a fixed weight. Defined over the distance between her action and the average action across all agents, this assumed "beauty contest" component of utility not only gives rise to the commonality role of public information, but also fixes the intensity of this commonality role. As a result, when the fixed weight is great and public information is noisy enough, the fixed commonality role dominates the diminishing information role and public information becomes detrimental to social welfare, which is defined as the negative of the average mean-squared error between individual action and the true state.

The following exercise gives us a glance at the importance of the endogenous link between the dual role of public information. Recall that $R$ measures the intensity of the commonality role and that it is increasing in $\alpha$. Now we fix $R$ to be a constant, $r$, so that the commonality role is decoupled from the information role.

Observation 1. When the Keynesian-beauty-contest effect is fixed at $r$, provisions of public information decrease market efficiency if and only if $r$ and $\alpha$ are such that

$$
\alpha<(1-r)\left(\beta+\rho_{1}\right)\left(1-\frac{2\left(\beta+\rho_{1}\right)}{\rho}(1-r)\right)
$$

and

$$
1-\frac{\rho}{2\left(\beta+\rho_{1}\right)}<r<1
$$


In the sense that fixing an endogenous variable to a constant inherently has too many degrees of freedom, Observation 1 is more a back-of-the-envelope calculation than a rigorous statement. However, it gives some clues about the importance of the endogenous link between the dual role of public information in determining its market efficiency consequences. When the public information is relatively noisy (condition 9) and the Keynesian-beauty-contest effect is fixed at a high level (condition 10), provisions of public information reduce market efficiency. In this sense, conditions 9 and 10 resemble condition 20 in Morris and Shin (2002). Therefore, the comparison of Proposition 2 and Observation 1 suggests that the detrimental social welfare effect of public information in Morris and Shin (2002) may result from the assumed "beauty contest" utility, an observation that warrants further investigation.

\section{Conclusion}

I study the market efficiency consequences of accounting disclosure in the context of stock markets as a Keynesian beauty contest. In such markets, public information performs both an information role and a commonality role. Because the dual role of public information is endogenously linked to each other via the quality of public information, disclosure of public information, however noisy it is, always brings stock prices closer to the fundamental value. Transparency should not be compromised on grounds of the Keynesian-beauty-contest effect.

Accounting disclosure is a distinct feature of modern corporations characterized by dispersed ownership. Previous research on accounting disclosure has mainly focused on agency problems and differential information among investors. This paper provides one example that dispersed ownership has other important consequences for accounting disclosure that have not received the 
attention they deserve. It opens up many new opportunities for future research. The Keynesianbeauty-contest effect may have substantial implications for the trade-off between public and private channels to disclose corporate information, the relation between information quality and cost of capital, and the relation between earnings and stock prices.

Another promising direction is to include real effects of accounting disclosure so as to examine the allocational efficiency consequences of accounting disclosure in a Keynesian-beauty-contest stock market. Since allocational efficiency may diverge from market efficiency, such an extension complements this study and deepens our understanding of the real consequences of accounting disclosure in a Keynesian-beauty-contest stock market. 


\section{Appendix}

Proof of Proposition 1. I solve for the model in five steps.

Step 1: Previous work has shown that for an economy in which investors have CARA utility functions and the payoff of the security is normally distributed, an investor $i$ 's demand for the risky security is described by equation 3 .

Step 2: The information structure in period 1.

Assume

$$
p_{1}=b z+c \theta-d s_{1}
$$

For investor $i$, she interprets $p_{1}$ as an independent signal, $p_{1}^{*}$, with precision $\rho$.

$$
\begin{aligned}
p_{1}^{*}=\frac{1}{c}\left(p_{1}-b z\right) & =\theta-\frac{d}{c} s_{1} \\
\rho & =\left(\frac{c}{d}\right)^{2} \gamma_{1}
\end{aligned}
$$

Correspondingly, her information set is $I_{1 i}=\left(z, p_{1}^{*}, x_{1 i}\right)$. Notice that $p_{1}^{*}$ is the same for all investors although they have differential private information. Her belief about the fundamental value $\theta$ is characterized by

$$
E_{i}\left[\theta \mid I_{1 i}\right]=\frac{\alpha z+\rho p_{1}^{*}+\beta x_{1 i}}{\alpha+\rho+\beta}
$$

and

$$
\operatorname{Var}_{i}\left[\theta \mid I_{1 i}\right]=\frac{1}{\alpha+\rho+\beta}
$$

The estimate of the variance is independent of the realization of signals and thus the same across investors. 
Step 3: The information structure in period 2.

Assume

$$
p_{2}=a_{2} p_{1}+b_{2} z+c_{2} \theta-d_{2} s_{2}
$$

Given the assumption that both $\mathrm{z}$ and $p_{1}^{*}$ are available to investors in period 2, investor $i$ in period 2 starts with a prior about $\theta, \frac{\alpha z+\rho p_{1}^{*}}{\alpha+\rho}$, with a precision of $\alpha+\rho$. Moreover, she also learns from $p_{2}$. Given her knowledge about $\mathrm{z}$ and $p_{1}^{*}$, the independent signal she can extract from $p_{2}$ is $p_{2}^{*}$, with precision $\rho_{2}$.

$$
\begin{array}{r}
p_{2}^{*}=\frac{1}{c_{2}}\left(p_{2}-a_{2} p_{1}-b_{2} z\right)=\theta-\frac{d_{2}}{c_{2}} s_{2} \\
\rho_{2}=\left(\frac{c_{2}}{d_{2}}\right)^{2} \gamma_{2}
\end{array}
$$

Thus her information set is $I_{2 i}=\left(p_{1}^{*}, z, p_{2}^{*}, x_{2 i}\right)$.

Conditional on $I_{2 i}$, she forms her belief of $\theta$ as follows:

$$
\begin{array}{r}
E_{i}\left[\theta \mid I_{2 i}\right]=\frac{\alpha z+\rho p_{1}^{*}+\beta x_{2 i}+\rho_{2} p_{2}^{*}}{\alpha+\rho+\beta+\rho_{2}} \\
\operatorname{Var}_{i}\left[\theta \mid I_{2 i}\right]=\frac{1}{\alpha+\rho+\beta+\rho_{2}}
\end{array}
$$

Again the estimate of the variance is independent of the realization of individual investors' private signals and thus identical across investors.

Step 4: Solve for $p_{2}$. 
According to equation 3 , investor $i$ 's demand conditional on $I_{2 i}$ is

$$
\begin{aligned}
D_{2 i} & =\frac{\tau\left(E_{i}\left[\theta \mid I_{2 i}\right]-p_{2}\right)}{\operatorname{Var}_{i}\left[\theta \mid I_{2 i}\right]} \\
& =\tau\left[\alpha z+\rho p_{1}^{*}+\beta x_{2 i}+\rho_{2} p_{2}^{*}-\left(\alpha+\rho+\beta+\rho_{2}\right) p_{2}\right] \\
& =\tau\left[\alpha z+\rho \frac{1}{c}\left(p_{1}-b z\right)+\beta x_{2 i}+\rho_{2} \frac{1}{c_{2}}\left(p_{2}-a_{2} p_{1}-b_{2} z\right)-\left(\alpha+\rho+\beta+\rho_{2}\right) p_{2}\right] \\
& =\tau\left[\left(\alpha-\frac{b}{c} \rho-\frac{b_{2}}{c_{2}} \rho_{2}\right) z+\left(\frac{1}{c} \rho-\frac{a_{2}}{c_{2}} \rho_{2}\right) p_{1}+\beta x_{2 i}-\left(\alpha+\rho+\beta+\left(1-\frac{1}{c_{2}}\right) \rho_{2}\right) p_{2}\right]
\end{aligned}
$$

$p_{2}$ is determined by aggregating individual investors' demands and equating it with the aggregate supply.

$$
p_{2}=\frac{\left(\alpha-\frac{b}{c} \rho-\frac{b_{2}}{c_{2}} \rho_{2}\right) z+\left(\frac{1}{c} \rho-\frac{a_{2}}{c_{2}} \rho_{2}\right) p_{1}+\beta x_{2 i}-\frac{s_{2}}{\tau}}{\left(\alpha+\rho+\beta+\left(1-\frac{1}{c_{2}}\right) \rho_{2}\right)}
$$

The coefficients array $\left(a_{2}, b_{2}, c_{2}, d_{2}\right)$ are determined by comparing coefficients in equation A- 6 with those in equation A-4.

$$
a_{2}=\frac{\frac{1}{c} \rho}{\alpha+\rho+\beta+\rho_{2}}, b_{2}=\frac{\alpha-\frac{b}{c} \rho}{\alpha+\rho+\beta+\rho_{2}}, c_{2}=\frac{\beta+\rho_{2}}{\alpha+\rho+\beta+\rho_{2}}, d_{2}=\frac{1}{\beta \tau} c_{2}
$$

and

$$
\rho_{2}=\beta^{2} \tau^{2} \gamma_{2}
$$

Step 5: Solve for $p_{1}$.

Investor $i$ who purchases stocks in period 1 does not hold them until the firm is liquidated; instead, she resells them at the price of $p_{2}$. Her demand, according to equation 3 , is shaped by her expectation about $p_{2}$, which is different from her expectation about $\theta$.

In period 1 , investor $i$ 's belief about $p_{2}$ is characterized by

$$
\begin{aligned}
& E_{i}\left[p_{2} \mid I_{1 i}\right]=\frac{\frac{1}{c} \rho}{\alpha+\rho+\beta+\rho_{2}} p_{1}+\frac{\alpha-\frac{b}{c} \rho}{\alpha+\rho+\beta+\rho_{2}} z+\frac{\beta+\rho_{2}}{\alpha+\rho+\beta+\rho_{2}} E_{i}\left[\theta \mid I_{1 i}\right] \\
& =\frac{\frac{1}{c} \rho}{\alpha+\rho+\beta+\rho_{2}} p_{1}+\frac{\alpha-\frac{b}{c} \rho}{\alpha+\rho+\beta+\rho_{2}} z+\frac{\beta+\rho_{2}}{\alpha+\rho+\beta+\rho_{2}} \frac{\alpha z+\rho p_{1}^{*}+\beta x_{1 i}}{\alpha+\rho+\beta} \\
& =\frac{1}{\alpha+\rho+\beta+\rho_{2}}\left[\left(1+\frac{\beta+\rho_{2}}{\alpha+\rho+\beta}\right)\left(\alpha-\frac{b}{c} \rho\right) z+\frac{\beta+\rho_{2}}{\alpha+\rho+\beta} \beta x_{1 i}+\left(1+\frac{\beta+\rho_{2}}{\alpha+\rho+\beta}\right) \frac{1}{c} \rho p_{1}\right]
\end{aligned}
$$


and

$$
\begin{aligned}
\operatorname{Var}_{i}\left[p_{2} \mid I_{1 i}\right] & =\left(\frac{\beta+\rho_{2}}{\alpha+\rho+\beta+\rho_{2}}\right)^{2} \operatorname{Var}_{i}\left[\theta \mid I_{1 i}\right]+\left(\frac{\beta+\rho_{2}}{\alpha+\rho+\beta+\rho_{2}}\right)^{2} \frac{1}{\beta^{2} \tau^{2} \gamma_{2}} \\
& =\frac{\left(\beta+\rho_{2}\right)^{2}}{\left(\alpha+\rho+\beta+\rho_{2}\right)} \frac{1}{(\alpha+\rho+\beta) \rho_{2}}
\end{aligned}
$$

Her demand is $D_{i}$.

$$
\begin{aligned}
D_{i}= & \frac{\tau\left(E_{i}\left[p_{2} \mid I_{1 i}\right]-p_{1}\right)}{\operatorname{Var}_{i}\left[p_{2} \mid I_{1 i}\right]} \\
& =\frac{\tau\left[\frac{1}{\alpha+\rho+\beta+\rho_{2}}\left(\left(1+\frac{\beta+\rho_{2}}{\alpha+\rho+\beta}\right)\left(\alpha-\frac{b}{c} \rho\right) z+\frac{\beta+\rho_{2}}{\alpha+\rho+\beta} \beta x_{1 i}+\left(1+\frac{\beta+\rho_{2}}{\alpha+\rho+\beta}\right) \frac{1}{c} \rho p_{1}\right)-p_{1}\right]}{\operatorname{Var}_{i}\left[p_{2} \mid I_{1 i}\right]} \\
& =\frac{\tau \rho_{2}}{\beta+\rho_{2}}\left[\left(\alpha-\frac{b}{c} \rho\right) \frac{1}{M} z+\beta x_{1 i}-\left(\left(\alpha-\frac{b}{c} \rho\right) \frac{1}{M}+\beta\right) p_{1}\right]
\end{aligned}
$$

where

$$
M=\frac{1}{1+\frac{\alpha+\rho+\beta}{\beta+\rho_{2}}}=\frac{\beta+\rho_{2}}{\alpha+\rho+2 \beta+\rho_{2}}
$$

$p_{1}$ is determined by equating aggregate supply with aggregate demand.

$$
p_{1}=\frac{\left(\alpha-\frac{b}{c} \rho\right) \frac{1}{M} z+\beta \theta-\frac{\beta+\rho_{2}}{\tau \rho_{2}} s_{1}}{\left(\alpha-\frac{b}{c} \rho\right) \frac{1}{M}+\beta}
$$

The coefficient array $(b, c, d)$ are determined by comparing coefficients in equations A-1 and A-11.

$$
b=\frac{\alpha}{\alpha+\rho+\beta M}, c=\frac{\rho+\beta M}{\alpha+\rho+\beta M}, d=\frac{\rho+\beta M}{\alpha+\rho+\beta M} \frac{\beta+\rho_{2}}{\rho_{2}} \frac{1}{\beta \tau}
$$

and

$$
\rho=\left(\frac{\rho_{2}}{\beta+\rho_{2}}\right)^{2} \beta^{2} \tau^{2} \gamma_{1}
$$

So $p_{1}$ is solved for by plugging equation A-12 to equation A-1.

$$
p_{1}=\frac{\alpha}{\alpha+\rho+\beta M} z+\frac{\rho+\beta M}{\alpha+\rho+\beta M} \theta-\frac{\beta+\rho_{2}}{\rho_{2}} \frac{\rho+\beta M}{\alpha+\rho+\beta M} \frac{1}{\beta \tau}
$$


$p_{2}$ is determined by inserting equation A-12 and A-14 to equation A-7.

$$
p_{2}=\frac{1}{\alpha+\beta+\rho+\rho_{2}}\left[\alpha z+\left(\beta+\rho+\rho_{2}\right) \theta-\frac{\beta+\rho_{2}}{\rho_{2}} \frac{\rho}{\beta \tau} s_{1}-\frac{\left(\beta+\rho_{2}\right)}{\beta \tau} s_{2}\right]
$$

Since the coefficients $(b, c, d)$ and $\left(a_{2}, b_{2}, c_{2}, d_{2}\right)$ are unique, the linear rational expectations equilibrium in Proposition 1 is unique, too.

Proof of Lemma 1. Lemma 1 is proved by using the traditional solution to a single-period noisy rational expectations equilibrium, such as that in Diamond and Verrecchia (1981). The procedure is the same as that in the proof of Proposition 1, except that $E_{i}\left[p_{2} \mid I_{1 i}\right]$ and $\operatorname{Var}_{i}\left[p_{2} \mid I_{1 i}\right]$ in equation A-9 are replaced by $E_{i}\left[\theta \mid I_{1 i}\right]$ and $\operatorname{Var}_{i}\left[\theta \mid I_{1 i}\right]$.

Proof of Proposition 2. Proposition 2 is proved by showing that the partial derivative of PE with respect to $\alpha$ is positive.

Define $M^{\prime}=\frac{\partial M}{\partial \alpha}$. Thus, $M^{\prime}=-\frac{\beta+\rho_{2}}{\left(\alpha+2 \beta+\rho+\rho_{2}\right)^{2}}<0$.

$$
\begin{aligned}
P E & =\frac{1}{E_{s, z}\left(p_{1}-\theta\right)^{2}} \\
& =\frac{1}{E_{s, z}\left(b \epsilon_{z}-d s_{1}\right)^{2}} \\
& =\frac{1}{\frac{b^{2}}{\alpha}+\frac{d^{2}}{\gamma_{1}}} \\
& =\frac{1}{\frac{b^{2}}{\alpha}+\frac{c^{2}}{\rho}} \\
& =\frac{\rho(\alpha+\rho+\beta M)^{2}}{\alpha \rho+(\beta M+\rho)^{2}}
\end{aligned}
$$




$$
\begin{aligned}
\frac{\partial P E}{\partial \alpha}= & \frac{2 \rho(\alpha+\beta M+\rho)\left(1+\beta M^{\prime}\right)\left(\alpha \rho+(\rho+\beta M)^{2}\right)-\rho(\alpha+\beta M+\rho)^{2}\left(\rho+2(\rho+\beta M) \beta M^{\prime}\right)}{\left(\alpha \rho+(\rho+\beta M)^{2}\right)^{2}} \\
& =\frac{(\alpha+\beta M+\rho) \rho}{\left(\alpha \rho+(\rho+\beta M)^{2}\right)^{2}}\left[2 \beta^{2} M^{2}+3 \beta M \rho+\alpha \rho+\rho^{2}-2 \alpha \beta^{2} M M^{\prime}\right] \\
& >0
\end{aligned}
$$

Proof of Proposition 3. Proposition 3 is proved by showing that the partial derivate of $R$ with respect to $\alpha$ is positive.

$$
\begin{gathered}
R=1-\frac{1}{\frac{b}{c} / \frac{\hat{b}}{\hat{c}}}=\frac{\beta(1-M)+\rho_{1}(1-k)}{\beta+\rho_{1}} \\
\frac{\partial R}{\partial \alpha}=-\frac{\beta M^{\prime}}{\beta+\rho_{1}}>0
\end{gathered}
$$

Proof of Observation 1. Observation 1 is proved by showing that the partial derivative of PE with respective to $\alpha$, evaluated at $R=r=\frac{\beta(1-M)+\rho_{1}(1-k)}{\beta+\rho_{1}}$, is negative under condition 9 and 10 .

For notational convenience, define B as follows.

$$
B=\frac{\hat{b}}{\hat{c}}=\frac{\alpha}{\beta+\rho_{1}}
$$




$$
\begin{aligned}
P E & =\frac{1}{\frac{b^{2}}{\alpha}+\frac{c^{2}}{\rho}} \\
& =\frac{\frac{1}{c^{2}}}{\left(\frac{b}{c}\right)^{2} \frac{1}{\alpha}+\frac{1}{\rho}} \\
& =\frac{(1-R+B)^{2}}{\frac{B^{2}}{\alpha}+\frac{(1-R)^{2}}{\rho}} \\
& =\frac{\alpha \rho(1-R+B)^{2}}{B^{2} \rho+(1-R)^{2} \alpha}
\end{aligned}
$$

and

$$
\begin{aligned}
& \left.\frac{\partial P E}{\partial \alpha}\right|_{R=r}=\frac{\rho^{2}(1-r+B) \alpha^{2}}{\left(\beta+\rho_{1}\right)^{3}\left((1-r)^{2} \alpha+B^{2} \rho\right)^{2}} \\
& \quad\left[\alpha-(1-r)\left(\beta+\rho_{1}\right)\left(1-\frac{2\left(\beta+\rho_{1}\right)}{\rho}(1-r)\right)\right]
\end{aligned}
$$

Since $\alpha, \beta, \tau, \gamma_{1}$, and $\gamma_{2}$ are positive and finite, both $\mathrm{M}$ and $\mathrm{k}$ lie between zero and one. As a result, $0<r<1$. It could be verified that $\mathrm{A}-16<0$ is equivalent to conditions 9 and 10 . 


\section{References}

Admati, A.R., 1985, A Noisy Rational Expectations Equilibrium for Multi-Asset Securities Markets, Econometrica 53, 629-658.

Allen, F., S. Morris, and H.S. Shin, 2006, Beauty Contests and Iterated Expectations in Asset Markets, Review of Financial Studies 19, 719.

Anctil, R.M., J. Dickhaut, C. Kanodia, and B. Shapiro, 2004, Information Transparency and Coordination Failure: Theory and Experiment, Journal of Accounting Research 42, 159-195.

Bikhchandani, S., D. Hirshleifer, and I. Welch, 1998, Learning from the Behavior of Others: Conformity, Fads, and Informational Cascades, The Journal of Economic Perspectives 12, 151-170.

Black, F., 1986, Noise, The Journal of Finance 41, 529-543.

Brown, D.P., and R.H. Jennings, 1989, On technical analysis, Review of Financial Studies 2, 527551.

Brunnermeier, M.K., 2001, Asset Pricing Under Asymmetric Information: Bubbles, Crashes, Technical Analysis, and Herding (Oxford University Press).

Diamond, D.W., and R.E. Verrecchia, 1981, Information Aggregation in a Noisy Rational Expectations Economy, Journal of Financial Economics 9, 221-235.

Easley, D., and M. O'hara, 2004, Information and the Cost of Capital, The Journal of Finance 59, $1553-1583$.

Fama, E.F., 1970, Efficient Capital Markets: A Review of Theory and Empirical Work, The Journal of Finance 25, 383-417. 
FASB, 1978, Statements of Financial Accounting Concepts for Business Enterprises No. 1: Objectives of Financial Reporting by Business Enterprises, Stamford, Connecticut: Financial Accounting Standards Board.

Grossman, S., 1976, On the Efficiency of Competitive Stock Markets Where Trades Have Diverse Information, The Journal of Finance 31, 573-585.

Grossman, S.J., 1995, Dynamic Asset Allocation and the Informational Efficiency of Markets, The Journal of Finance 50, 773-787.

— and J.E. Stiglitz, 1980, On the Impossibility of Informationally Efficient Markets, The American Economic Review 70, 393-408.

Grundy, B.D., and M. McNichols, 1989, Trade and the revelation of information through prices and direct disclosure, Review of Financial Studies 2, 495-526.

Hayek, F.A., 1945, The Use of Knowledge in Society, The American Economic Review 35, 519-530.

Hirota, S., and S. Sunder, 2007, Price Bubbles Sans Dividend Anchors: Evidence from Laboratory Stock Markets , Journal of Economic Dynamics and Control 31, 1875-1909.

Hirshleifer, J., 1971, The Private and Social Value of Information and the Reward to Inventive Activity, The American Economic Review 61, 561-574.

Keynes, J.M., 1936, The general theory of employment interest and money (Macmillan London).

Lambert, R., C. Leuz, and R.E. Verrecchia, 2007a, Accounting Information, Disclosure, and the Cost of Capital, Journal of Accounting Research 45, 385-420. 
— , 2007b, Information Asymmetry, Information Precision, and the Cost of Capital , working paper.

Morris, S., and H.S. Shin, 2002, Social Value of Public Information, The American Economic Review 92, 1521-1534.

Plantin, G., H. Sapra, and H.S. Shin, 2007, Marking-to-Market: Panacea or Pandora's Box, Journal of Accounting Research forthcoming.

Shiller, R.J., 2000, Irrational Exuberance (Princeton, NJ: Princeton University Press).

Tobin, J., 1984, On the Efficiency of the Financial System, Lloyd's Bank Review 153, 1-15.

Walther, B.R., 2004, Discussion of Information Transparency and Coordination Failure: Theory and Experiment, Journal of Accounting Research 42, 197-205. 